ИЗВЕСТИЯ АКАДЕМИИ НАУК ЭСТОНСКОП ССР. ТОМ 25 ХИМИЯ * ГЕОЛОГИЯ. 1976, № 4

\title{
РАСПРОСТРАНЕНИЕ КОНОДОНТОВ И БЕЗЗАМКОВЫХ БРАХИОПОД В ЦЕРАТОПИГЕВОМ И ЛАТОРПСКОМ ГОРИЗОНТАХ СЕВЕРНОЙ ЭСТОНИИ
}

Настоящая работа посвящена изучению распространения конодонтов (В. Вийра) и основной группы макрофауны - беззамковых брахиопод (С. Мяги) по обнажениям Кейла-Коа (на западе) и Варангу (на востоке) Северной Әстонии в целях уточнения литологически нечетких границ

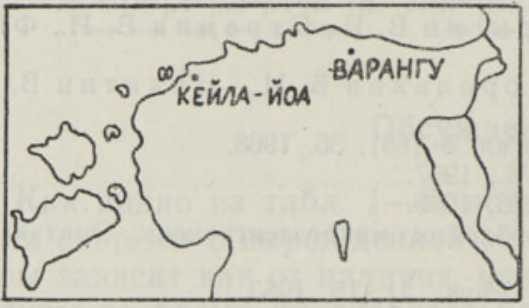

КЕЙЛА-ЙОА

BAPAHTY

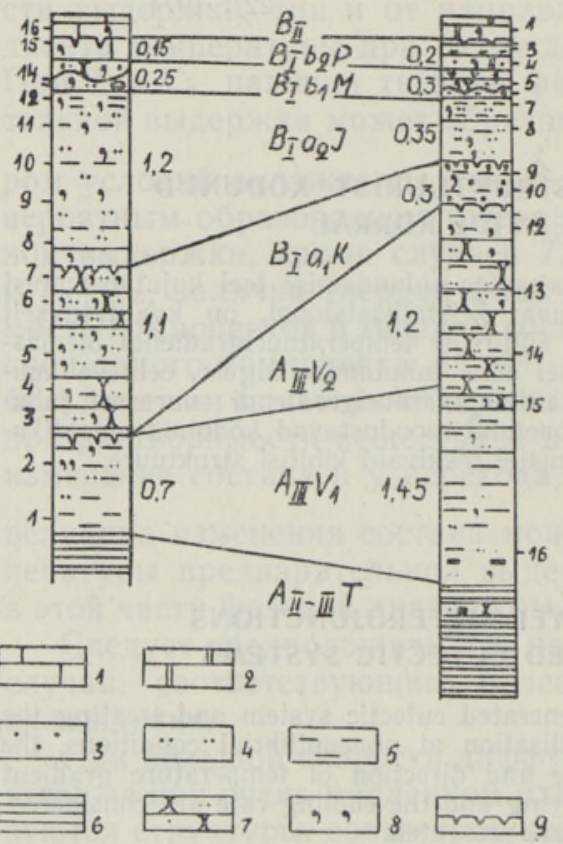
между варангуской пачкой цератопигевого и клоогаской пачкой латорпского горизонтов, а также между отдельными пачками латорпского горизонта (рисунок; Клеесмент, Мяги, 1975). Обзор послойного распределения б́рахиопод дается в основном по разрезу Кейла-Коа, так как в обн. Варангу они сильно измельчены, а поэтому трудно поддаются определению. Конодонты изучались по образцам из всего разреза латорпского горизонта и верхней части варангуской пачки цератопигевого горизонта (рисунок). В стратотипическом разрезе варангуской пачки их распределение

Схема расположения изученных обнажений и их стратиграфические колонки с указанием места взятия и номера проб.

$\mathrm{A}_{\mathrm{II}-\mathrm{III} \mathrm{T}}$ - тюрисалуская пачка; $\mathrm{A}_{\text {III }} \mathrm{V}_{1}, \mathrm{~A}_{\mathrm{III}} \mathrm{V}_{2}$ - нижняя и верхняя части варангуской пачки, подгоризонты цератопигевого горизонта; $\mathrm{B}_{\mathrm{Ia}}, \mathrm{B}_{\mathrm{I}} \mathrm{a}_{2}$ - нижняя и верхняя части хуннебергского подгоризонта латорпского горизонта: $\mathrm{B}_{1} \mathrm{a}_{1} \mathrm{~K}$ - клоогаская пачка, $\mathrm{B}_{\mathrm{I}} \mathrm{a}_{2} \mathrm{~J}$ - ируская пачка; $\mathrm{B}_{\mathrm{I}} \mathrm{b}_{1}, \mathrm{~B}_{\mathrm{I}} \mathrm{b}_{2}-$ нижняя и верхняя части биллингенского подгоризонта латорпского горизонта: $\mathrm{B}_{\mathrm{I}} \mathrm{b}_{1} \mathrm{M}$ - мяэкюлаская пачка, $\mathrm{B}_{1} \mathrm{~b}_{2} \mathrm{P}$ - пяйтеская пачка; $\mathrm{B}_{\mathrm{II}}$ - волховский горизонт.

1 - известняки, 2 - доломиты, 3 песчаники, 4-алевролиты, 5-глины, 6 аргиллиты, 7 - сильносцементированные алевролиты и песчаники, 8- глауконит, 9 - поверхности перерыва. 
детально проанализировано ранее (Вийра и др., 1970). Для выяснения распределения беззамковых брахиопод просматривались бороздовые пробы из слабосцементированных пород варангуской пачки и вышележащего хуннебергского подгоризонта по интервалам $0,2-0,4 \mu$, а в случае изменения состава пород - по интервалам 0,05-0,1 $\mu$ (рисунок).

Р аспределение конодон тов (табл. 1). В нижней части обоих изученных разрезов выделяется ассоциация конодонтовой зоны Scandodus varanguensis, приуроченная к варангуской пачке (Вийра и др., 1970; Вийра, 1974). Здесь найдены Drepanodus pristinus, D. aff. subarcuatus, D. numarcuatus, Acodus tetrahedron, A. firmus, Oistodus inaequalis, O. parallelus, Cordylodus angulatus, C. rotundatus, C. prion и др. Из них первые четыре вида встречены только в пределах варангуской пачки, а остальные распространены и в вышележащих слоях. Зональный вид Scandodus varanguensis найден вместе с перечисленными конодонтами в обн. Кейла-Йа. В верхней $(0,6$ м) части стратотипа варангуской пачки он не обнаружен, если не считать один сомнительный экземпляр из основания хуннебергского подгоризонта. Для верхней части варангуской пачки (в объеме по В. Вийра и др. (1970)) характерна ассоциация конодонтовой зоны, отсутствующая в этой пачке обн. Кейла-Коа. K ней относятся Drepanodus numarcuatus, D. amoenus, Scandodus vitreus.

Появление многочисленных новых видов конодонтов происходит на нижней границе латорпского горизонта - в основании клоогаской пачки. К типичным видам зоны Drepanodus proteus хуннебергского подгоризонта, кроме зонального вида, относятся Acodus deltatus, A. erectus, Acontiodus latus, Scandodus pipa, Drepanodus arcuatus и Distacodus aff. peracutus. В середине обн. Варангу, в верхней части хуннебергского подгоризонта - ируской пачке - к перечисленным формам прибавляются Paltodus inconstans, Oistodus contractus, O. linguatus, Drepanodus cyranoicus, D. conulatus. Распространение зонального Drepanodus proteus ограничивается данным подгоризонтом, большинство же других видов переходит в вышележащие слои. Например, Oistodus inaequalis и O. parallelus. Переходящие из подстилающей варангуской пачки (в объеме по В. Вийра и др. (1970)) Acodus firmus, Drepanodus? sp. п. исчезают в нижней половине хуннебергского подгоризонта - клоогаской пачке. В обн. Кейла-Йа последние экземпляры Cordylodus rotundatus встречаются в верхней части хуннебергского подгоризонта, в то время как в обн. Варангу морфологичеоки близкий к ним вид Cordylodus angulatus найден и в лежащих выше слоях биллингенского подгоризонта. Как видно из сказанного, в пределах хуннебергского подгоризонта картина распространения видов конодонтов несколько меняется. Однако эти изменения все же второстепенны и не столь резки, как на нижней границе подгоризонта.

Другая четкая смена комплексов конодонтов наблюдается на границе хуннебергского и биллингенского подгоризонтов (табл. 1; в Кейла-Иоа между уровнями проб 12 и 13 , в Варангу - между 7 и 6 ). В нижней части биллингенского подгоризонта - мяэкюлаской пачке - появляется богатый комплекс зоны Oistodus lanceolatus. Кроме зонального вида, этот комплекс представлен большим количеством Oistodus triangularis, O. delta, Scolopodus rex, Oepikodus smithensis. В верхней части биллингенского подгоризонта - пяйтеской пачке (обн. Варангу, пробы 2-4) появляются Prioniodus elegans, P. evae, Distacodus expansus, Prioniodina ? deflexa, Trichonodella flabellum. В самых верхних пробах обоих обнажений (16 в Кейла-Йоа и 1 в Варангу) уже попадаются конодонты зоны Cordylodus perlonglis: Oistodus complanatus, Prioniodina flabellum, Trichonodella alae, $T$, ? irregularis и др., относящиеся к волховскому горизонту. 


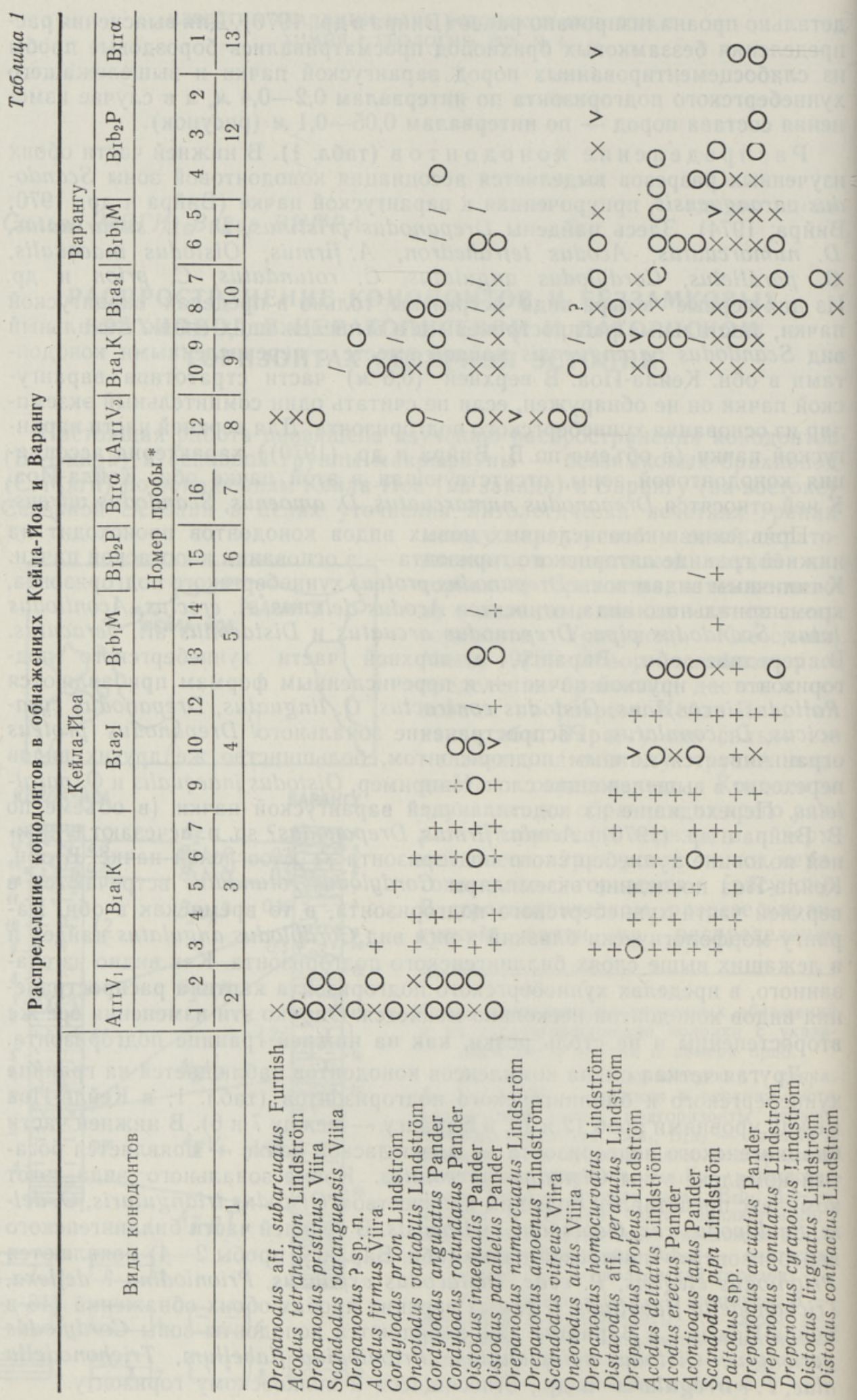




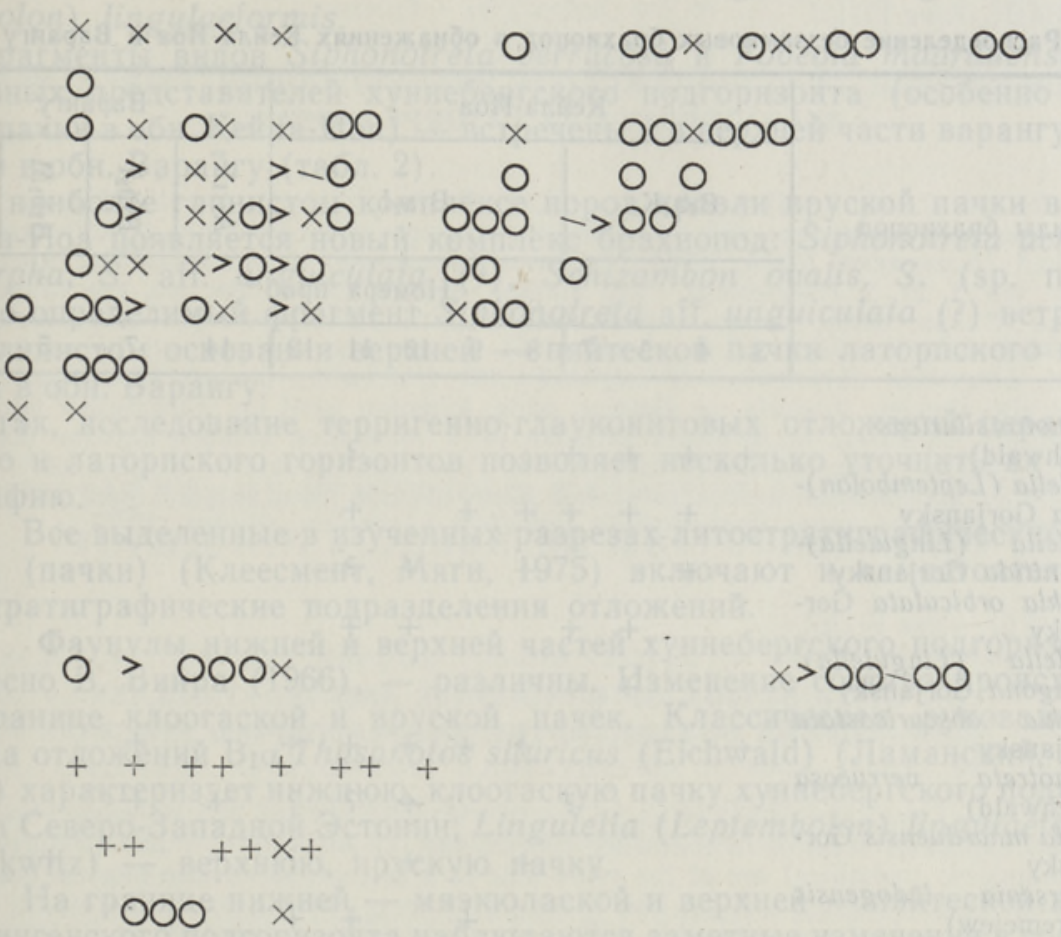

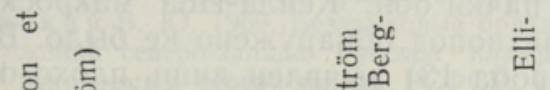

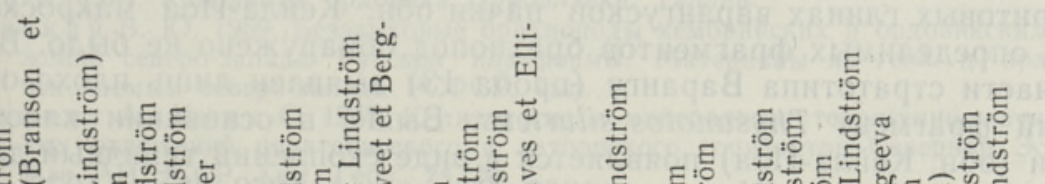

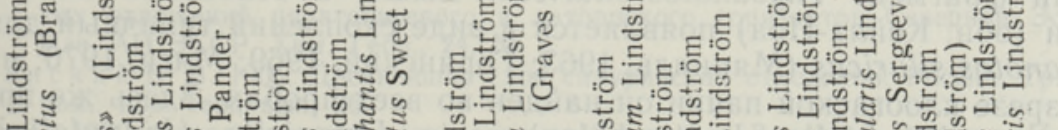

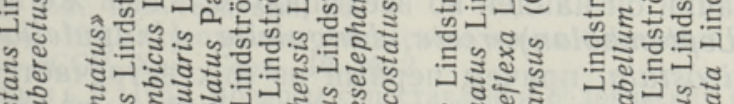

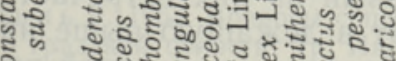

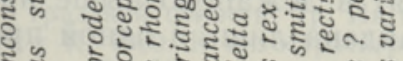
ต

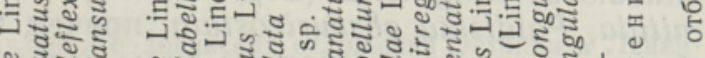

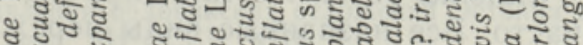

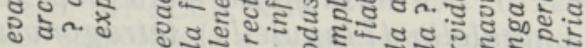

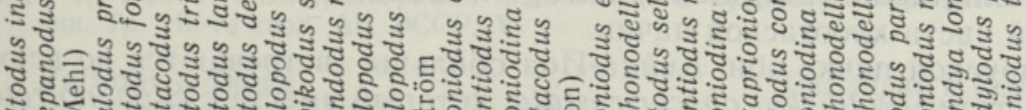

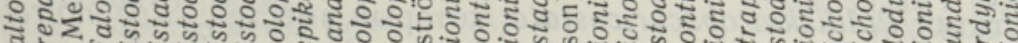
है क् 
Распределение беззамковых брахиопод в обнажениях Кейла-Иоа и Варангу

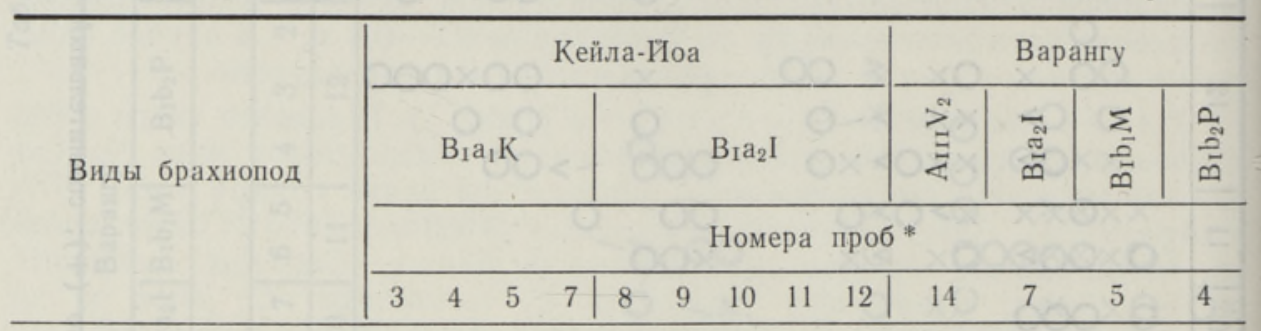

Thysanotos siluricus

(Eichwald)

Lingulella (Leptembolon)recta Gorjansky

Lingulella (Lingulella)(?) nitida Gorjansky

Paldiskia orbiculata Gorjansky

Lingulella (Lingulella) tetragona Gorjansky

Paldiskia obscuricostata Gorjansky

Siphonotreta verrucosa (Eichwald)

Foveola maarduensis Gorjansky

Helmersenia ladogensis (Jeremejew)

Lingulella (Leptembolon) lingulaeformis (Mickwitz)

Siphonotreta acrotretomorpha Gorjansky

Schizambon ovalis Gorjansky

Siphonotreta aff. unguiculata (?) (Eichwald)

Schizambon (sp. n. ?)

Orbiculoidea? sp. (shallochensis Reed?)

$$
\begin{aligned}
& ++++ \text { ? } \\
& +++++ \\
& +\quad+\quad+\text { ? } \\
& +++ \\
& + \\
& +4++4+ \\
& \text { ? }+ \text { ? }++ \\
& +\quad+\text { ? }+ \\
& +\quad+ \\
& +\quad+ \\
& + \\
& + \\
& \text { ? } \\
& +
\end{aligned}
$$

Р аспределение безза мковых брахиопод (табл. 2). В алевритовых глинах варангуской пачки обн. Кейла-Йоа макроскопических, определимых фрагментов брахиопод обнаружено не было. В верхней части стратотипа Варангу (проба 13) выявлен лишь плохо определимый фрагмент Thysanotos siluricus. Выше, в основании клоогаской пачки (обн. Кейла-Иоа) появляется в виде скоплений типичный для В $\mathrm{I}_{\mathrm{I}}$ Thysanotos siluricus (Мянниль, 1963; Горянский, 1969; Мяги, 1970; и др.). В разрезе клоогаской пачки он найден во всех пробах. Здесь же прослеживаются Lingulella (Leptembolon) recta, Lingulella (Lingulella) (?) nitida, Paldiskia obscuricostata, причем первый из них встречается особенно часто. Все названные виды переходят в лежащую выше ирускую пачку. Lingulella (Lingulella) tetragona найдена лишь в одной пробе из верхней части клоогаской пачки.

В ируской пачке обн. Кейла-Иоа обильны (встречаются во всех пробах) остатки Paldiskia obscuricostata, который вместе с Siphonotreta verrucosa распространен в той же пачке разреза Варангу. Здесь также появ- 
ляются Foveola maarduensis, Helmersenia ladogensis, Lingulella (Leptembolon) lingulaeformis.

Фрагменты видов Siphonotreta verrucosa и Foveola maarduensis основных представителей хуннебергского подгоризонта (особенно ируской пачки в обн. Кейла-Иоа) - встречены и в верхней части варангуской пачки в обн. Варангу (табл. 2).

В наиболее глинистом комплексе пород кровли ируской пачки в обн. Кейла-Йоа появляется новый комплекс брахиопод: Siphonotreta acrotretomorpha, S. aff. unguiculata (?), Schizambon ovalis, S. (sp. n. ?). Плохо определимый фрагмент Siphonotreta aff. unguiculata (?) встречен и в глинистом основании верхней - пяйтеской пачки латорпского горизонта в обн. Варангу.

Итак, исследование терригенно-глауконитовых отложений цератопигевого и латорпского горизонтов позволяет несколько уточнить их стратиграфию.

1. Все выделенные в изученных разрезах литостратиграфические единицы (пачки) (Клеесмент, Мяги, 1975) включают и самостоятельные биостратиграфические подразделения отложений.

2. Фаунулы нижней и верхней частей хуннебергского лодгоризонта, согласно В. Вийра (1966), - различны. Изменение состава происходит на границе клоогаской и ируской пачек. Классическая руководящая форма отложений $\mathrm{B}_{\mathrm{I}}$. Thysanotos siluricus (Eichwald) (Ламанский, 1905; и др.) характеризует нижнюю, клоогаскую пачку хуннебергского подгоризонта Северо-Западной Эстонии, Lingulella (Leptembolon) lingulaeformis (Mickwitz) - верхнюю, ирускую пачку.

3. На границе нижней - мяэкюлаской и верхней - пяйтеской пачек биллингенского подгоризонта наблюдаются заметные изменения в составе комплекса конодонтов. В серых глинах Северо-Восточной Эстонии (Орвику, 1960) и в переходных песчаных доломитах на границе пачек состав конодонтов также переходный. Однако в них найдена характерная для пяйтеской пачки руководящая форма (по Вийра, 1970) Trichonodella flabellum Lindström.

\section{Л И ТЕРА Т У Р А}

В и й р а В. 1966. Распространение конодонтов в нижнеордовикских отложениях разреза Сухкрумяги (г. Таллин). Изв. АН ЭССР, Сер. физ.-матем. и техн. наук, 15 , № 1.

В и й р а В. 1970. Конодонты ордовика Прибалтики. Автореф. канд. дис. Таллин.

В и й р а В., К и в и я г Э.; Л о ог А. 1970. О литологии и возрасте варангуской пачки (тремадок Северной Эстонии). Изв. АН ЭССР, Хим. Геол., 19, № 2.

В и йр а В. 1974. Конодонты ордовика Прибалтики. Таллин.

Г ор я н с к й В. Ю. 1969. Беззамковые брахиоподы кембрийских и ордовикских отложений северо-запада Русской платформы. Материалы по геол. и полезным ископаемым северо-запада РСФСР, вып. 6.

Клеесмент А., М яги С. 1975. К литологии и минералогии терригенно-глауконитовых отложений цератопигевого и латорпского горизонтов Северной Эстонии. Изв. АН ЭССР, Хим. Геол., 24, № 1.

Л а м а н ск ий В. В. 1905. Древнейшие слои силурийских отложений России. Тр. Геол. ком., нов. сер., вын. 26.

М я г С. 1970. Отложения онтикаского яруса Средней и Западной Эстонии. Изв. АН ЭССР, Хим. Геол., 19, № 2.

М янни ль Р. 1963. Вопросы сопоставления ордовикских отложений Эстонии и Ленинградской области. Тр. Ин-та геол. АН ЭССР, ХІІІ.

О р в к у К. 1960. К литостратиграфии волховского и кундаского горизонтов в Эстонии. Тр. Ин-та геол. АН ЭССР, V.

Ннститут геологии

Академии наук Эстонской ССР
Поступила в редакцию $8 / \mathrm{X} 1975$ 
Silvi MÄGI, Viive VIIRA

\section{KONODONTIDE JA PUUDULUKULISTE BRAHHIOPOODIDE ESINEMUSEST TSERATOPUOGE JA LATORPI LADEMES}

Keila-Joa (Loode-Eesti) ja Varangu (Kirde-Eesti) paljandite tseratopuiüge ja latorpi lademe uurimise tulemusena võib teha järgmisi stratigraafilisi järeldusi. 1. Kōik eraldatud kihistikud (Клеесмент, Мяги, 1975) sisaldavad omakorda biostratigraafilisi komplekse (joonis, tab. 1, 2). 2. Hunnebergi vöö alumise, klooga, ja ülemise, iru, osa faunula on erinevad (Вийра, 1966); muutus toimub kihistike piiril. Klassikaline $\mathrm{B}_{1} \alpha$ tüüploom Thysanotos siluricus (Eichwald) (Ламанский, 1905) iseloomustab Pōhja-Eesti hunnebergi vöö alumist, Lingulella (Leptembolon) lingulaeformis (Mickwitz) ülemist kihistikku. 3. Billingeni vöö alumise, mầeküla, ja ülemise, päite, kihistiku piiril on märgatavad muutused konodontide koosluses. Kirde-Eestis kilistike piiril esinevates hallides savides (Орвику, 1960) ja üleminekulistes liivakates dolomiitides (Varangu, proovid 3, 4; Клеесмент, Мяги, 1975) on ka konodontide koosius suhteliselt üleminekuline, kuid sisaldab juba päite kihistikule iseloomulikku vormi Trichonodella flabellum Lindström (Вийра, 1970).

\section{Silvi MAGI, Viive VIIRA}

\section{ON DISTRIBUTION OF CONODONTS AND INARTICULATE BRACHIOPODS IN CERATOPYGE AND LATORPIAN STAGES}

The faunal characterization of Keila-Joa (Northwest Estonia) and Varangu (Northeast Estonia) exposures resulted in following conclusions: 1) All separable lithostratigraphical rock complexes (members) are at the same time to a certain extent also binstratigraphical complexes (Figure, Tab. 1, 2). 2) The Klooga Member belong to the Latorpian Stage. 3) Faunal differences are noticeable within the Hunnebergian Substage in its upper and lower part (see Вийра, 1966). The change line is the boundary between the Klooga and Iru members. 4) The lower, the Mäeküla Member, and the upper, the Päite Member of the Billingen Substage bear remarkable faunal differences. 5) The grey clays (Орвінкy, 1960) and sandy dolomites at the boundary of the Mäeküla and Päite members, with their renewing conodont fauna, indicate that these transitional members belong to the more recent Päite Member. 